\title{
PEWARISAN TEKNOLOGI LOGAM PADA MASYARAKAT LAMPUNG
}

\section{The Inheritance of Metal Technology in Lampung Society}

\author{
Nanang Saptono, Rusyanti, Endang Widyastuti \\ Balai Arkeologi Jawa Barat \\ Jalan Raya Cinunuk km. 17, Cileunyi, Bandung \\ E-mail: nanangsaptono@gmail.com
}

\begin{abstract}
Metal technology is known to the public starting at the end of the cultivation period. The early days of metal technology recognition are often called the paleometalic period. In Austronesian society, metal technology is often controlled by the Dongson culture. Culture developed from Vietnam around 1000 BC or early AD. From Vietnam spread throughout Southeast Asia including in the archipelago. Some of the objects of the Dongson culture that were found were in the form of bronze objects such as nekara, bronze vessels, and bronze axes. In a younger period, namely during the Hindu-Buddhist period (Classical Period) in Lampung, many metal objects were also found. Bronze objects from the paleometalic period such as nekara and bronze vessels were probably of great importance. Based on these objects, it appears that there are a cultural inheritance of metal processing technology (bronze) deposits from the paleometalic period to the Islamic-colonial period. This study seeks to reveal the existence of this cultural inheritance. The disclosure of cultural inheritance will be reviewed based on the research findings in the Mount Rajabasa area. Based on this review, the question of cultural inheritance will be known.
\end{abstract}

Keywords: technology, inheritance, metal, Islamic-Colonial period

\begin{abstract}
Abstrak
Teknologi logam dikenal masyarakat mulai pada akhir masa bercocok tanam. Masa awal dikenalnya teknologi logam sering juga disebut masa paleometalik. Pada masyarakat Austronesia, teknologi logam sering kali dikaitkan pula dengan budaya Dongson. Kebudayaan ini berkembang dari Vietnam pada sekitar 1000 SM atau awal Masehi. Dari Vietnam menyebar ke seluruh Asia Tenggara termasuk nusantara. Beberapa benda hasil budaya Dongson yang ditemukan adalah berupa benda-benda perunggu seperti misalnya nekara, bejana perunggu, dan kapak perunggu. Pada masa-masa yang lebih muda yaitu pada masa Hindu-Buddha (Masa Klasik) di Lampung banyak juga ditemukan benda-benda logam. Pada benda-benda perunggu yang berasal dari masa paleometalik seperti nekara dan bejana perunggu mungkin merupakan benda impor. Berdasarkan benda-benda tersebut terlihat ada pewarisan budaya khususnya teknologi pengolahan logam (perunggu) dari masa paleometalik hingga masa Islam-Kolonial. Kajian ini berusaha untuk mengungkap adanya pewarisan budaya tersebut. Pengungkapan adanya pewarisan budaya akan diulas berdasarkan temuan-temuan hasil penelitian di kawasan Gunung Rajabasa. Berdasarkan ulasan tersebut akan diketahui adanya pewarisan budaya dimaksud.
\end{abstract}

Kata kunci: teknologi, pewarisan, logam, masa Islam-Kolonial 


\section{PENDAHULUAN}

$\mathrm{P}_{\mathrm{b}}$ osisi kepulauan nusantara dia antara dua benua dan dua samudra menjadikannya sebagai kawasan yang mudah dikunjungi dan dilalui berbagai bangsa. Sejak masa prasejarah telah terjadi migrasi manusia dari berbagai daratan menuju kawasan tropis nusantara. Pada kala Pleistosen telah terjadi migrasi manusia purba ke berbagai wilayah. Australopithecus diketahui jejaknya di Afrika Selatan dan Afrika Timur merupakan manusia purba tertua yang selanjutnya berevolusi dan bermigrasi ke seluruh penjuru. Pithecanthropus, manusia purba yang menunjukkan mengalami evolusi ke manusia modern banyak ditemukan di Asia Tenggara dan Asia Timur. Selain di kedua daerah itu, Pithecanthropus juga ditemukan di Afrika Timur dan Afrika Utara. Berdasarkan temuan-temuan jejak manusia purba inilah para ahli berkesimpulan bahwa manusia berasal dari satu tempat lalu menyebar ke daerah lain (Poesponegoro \& Notosusanto, 2009). Menurut teori out of Africa migrasi manusia dari daratan Afrika kemudian menyebar ke berbagai daerah hingga akhirnya sampai di Pulau Jawa terjadi dalam dua gelombang yaitu migrasi manusia purba dan manusia modern $(H$. sapiens) sebagai penerus manusia purba (Fachruliansyah, 2018).

Migrasi disertai persebaran budaya berlangsung terus hingga masa sekarang. Pada sekitar 2000 BP terjadi migrasi para penutur Austronesia yang ditandai dengan artefak alat neolitik. Selanjutnya, seiring dengan kemajuan di bidang pelayaran dan perdagangan regional global, hingga sekitar abad ke-4 - 5 Masehi berlangsung migrasi masyarakat yang semakin kompleks. Budaya penanda pada periode ini adalah praktek penguburan tempayan yang merupakan tradisi berlanjut prasejarah (Neolitik), bendabenda logam pengaruh Budaya Dongson, dan Megalitik (Simanjuntak, 2015). Migrasi penutur Austronesia ke Asia Tenggara dan Pasifik juga membawa pengetahuan tentang pertanian (padi, jewawut, tebu, ubi dan keladi raksasa) budaya akuatik, domestikasi ternak (babi, anjing, ayam), teknologi pelayaran, pembuatan gerabah, penggunaan beliung persegi, perhiasan kerang, tenun dan kebiasaan makan sirih (Bellwood, 2000). Berkembangnya kebudayaan Dongson di Asia Tenggara bersamaan dengan berkembangnya budaya religi, pertanian, dan teknologi.

Kebudayaan Dong Son merupakan berkembang di Vietnam pada zaman perunggu (Bronze Age), mula-mula berkembang di lembah Sungai Merah (Song Hong) di wilayah utara Vietnam. Pada waktu itu di Vietnam sudah berdiri Kerajaan Van Lang dan Au Lac. Melalui aktivitas kerajaan seperti perdagangan, budaya Dongson memberi pengaruh besar di berbagai wilayah Asia Tenggara, termasuk wilayah kepulauan Nusantara pada sekitar tahun 1000 SM hingga awal abad Masehi. Masyarakat Dong Son, yang juga dikenal dengan sebutan Lac atau Lac Viet, adalah masyarakat yang bermata pencaharian sebagai petani dan peternak (Jusoh, 2016; Wijaya, 2013).

Benda logam terutama perunggu yang merupakan hasil budaya Dongson banyak ditemukan di wilayah nusantara. Beberapa benda perunggu budaya Dongson juga ditemukan di wilayah Lampung. Selain benda-benda perungu hasil budaya Dongson, di Lampung juga ditemukan beberapa benda logam perunggu. Benda-benda berbahan perunggu ditemukan pada situs-situs yang berasal dari masa yang lebih muda. Berdasarkan temuan-temuan tersebut, kajian 
ini akan membahas permasalahan seputar adanya pewarisan teknologi logam pada masyarakat Lampung. Kajian dilakukan melalui analisis terhadap beberapa objek benda perunggu yang ditemukan di Lampung khususnya di daerah Lampung Selatan. Metode pembahasannya melalui analisis morfologis terhadap tinggalan benda logam tersebut.

\section{PEMBAHASAN}

\section{Persentuhan dengan Budaya Logam}

Kehidupan manusia dengan budaya bercocok tanam semakin meningkat dengan dikenalnya teknologi pengolahan logam. Penemuan teknik peleburan, pencampuran, penempaan, dan pencetakan jenis-jenis logam telah menghasilkan berbagai barang termasuk untuk keperluan bercocok tanam. Sebelum dikenal teknik pencampuran, peleburan tembaga dan emas sudah lebih dulu dikenal karena kedua jenis logam ini sangat mudah dilebur. Penemuan teknik peleburan dan pencampuran telah menghasilkan benda-benda yang lebih kuat. Bahan campuran inilah yang dikenal dengan perunggu (Poesponegoro \& Notosusanto, 2009, hal. 293).

Beberapa perkakas bercocok tanam yang terbuat dari logam, umumnya perunggu atau besi, semakin meningkatkan produksi pangan sehingga sering terjadi surplus. Berdasarkan temuan-temuan artefak sejenis budaya logam di Indonesia mendapat pengaruh dari budaya Dongson dari Vietnam. Bendabenda perunggu hasil budaya Dongson misalnya nekara, bejana perunggu, kapak corong, candrasah, arca-arca perunggu, dan perhiasan. Di Lampung, pernah ditemukan benda-benda perunggu (Gambar 1). Di Desa Gedung Aji, Tulangbawang pernah ditemukan nekara. Di Desa Sriminosari, Kecamatan Labuhan Maringgai, Lampung Timur pernah ditemukan nekara dan bejana perunggu. Benda-benda itu sekarang tersimpan di Museum Ruwa Jurai.
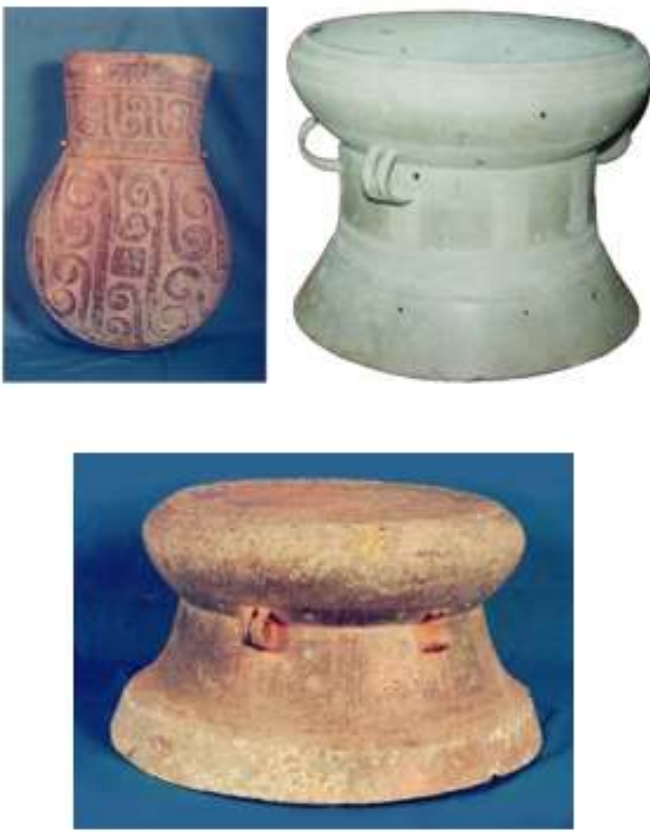

Gambar 1. Benda-benda perunggu yang ditemukan di Lampung (Sumber: Dokumen Museum Ruwa Jurai)

\section{Benda-Benda Logam di Lampung}

Di Museum Ruwa Jurai tersimpan beberapa benda, diantaranya merupakan benda berlatarkan pada budaya HinduBuddha yang ditemukan dari kawasan Way Sekampung (Tim Penelitian, 2009). Bendabenda tersebut adalah sebagai berikut.

\section{- Arca Dewi Sri (1)}

Arca dengan nomor koleksi 2634 (No. Inventaris 04.104; No. Registrasi 2201), ditemukan di Desa Banjar Agung, Kecamatan Talang Padang, Kabupaten Tanggamus (Gamabr 2). Arca berukuran tinggi keseluruhan $23,5 \mathrm{~cm}$ terbuat dari 
bahan perunggu, pada beberapa bagian berlapis emas. Arca digambarkan dengan sikap badan berdiri tegak (samabangga) di atas lapik teratai (padmasana).

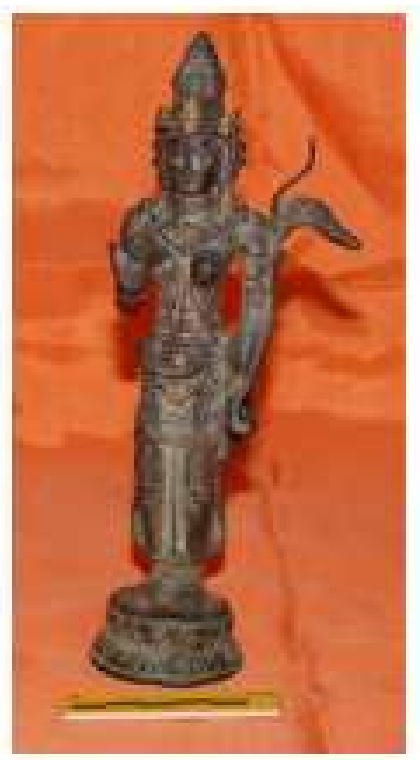

Gambar 2. Arca Dewi Sri yang ditemukan di Desa Banjar Agung (Sumber: Dokumen Balai Arkeologi Jawa Barat, 2009).

\section{- Arca Dewi Sri (2)}

Arca Dewi Sri (2) dengan nomor koleksi 3976 ditemukan di Pekon Rantau Tijang, Kecamatan Pugung, Kabupaten Tanggamus. Ukuran arca, tinggi keseluruhan $19 \mathrm{~cm}$ berbahan perunggu, pada beberapa bagian berlapis emas. Arca digambarkan dengan sikap badan berdiri tegak (samabangga) di atas lapik teratai (padmasana). Tangan kanan menjulur ke bawah dengan telapak tangan terbuka mengarah ke atas. Sikap seperti ini disebut varahasta atau varadahasta. Tangan kiri menjulur ke bawah telapak mendatar menjepit tangkai padi.

\section{- Arca Durgamahisasuramardini}

Arca dengan nomor koleksi 3685 (No. Inventaris. 04.287; No. Registrasi 3858) ini ditemukan di Desa Wana, Kecamatan
Labuhan Maringgai, Kabupaten Lampung Timur (Gambar 3). Arca berukuran tinggi $20,5 \mathrm{~cm}$, terbuat dari bahan perunggu. Durgamahisasuramrdini diwujudkan dalam sikap berdiri di atas kerbau dengan kaki terbuka, badan agak miring (sikap alidha).

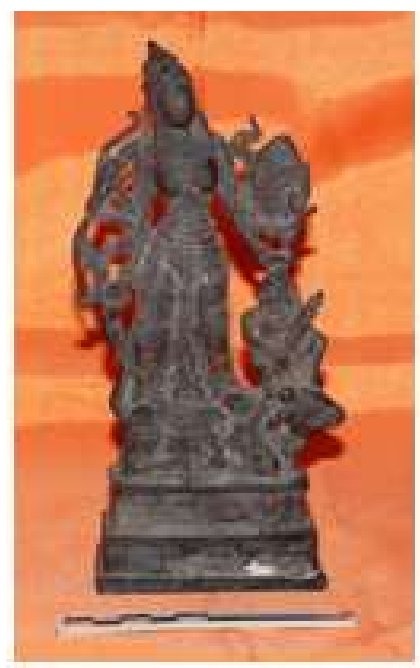

Gambar 3. Arca Durgamahisasuramrdini ditemukan di Desa Wana (Sumber: Dokumen Balai Arkeologi Jawa Barat, 2009).

\section{- Arca Buddha}

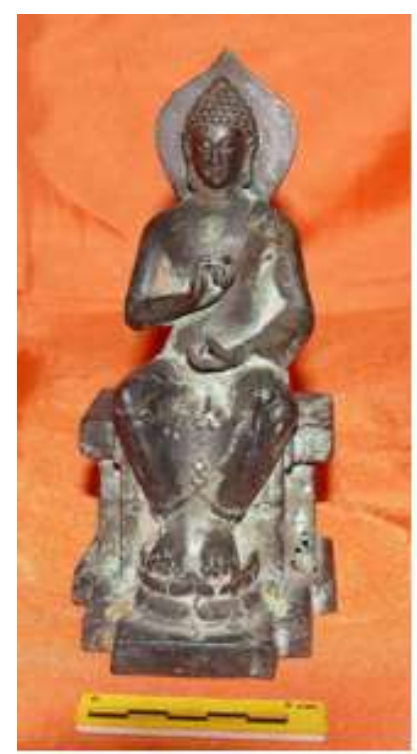

Gambar 4. Arca Buddha ditemukan di Desa Ketapang (Sumber: Dokumen Balai Arkeologi Jawa Barat, 2009). 
Arca Buddha dengan nomor koleksi 3044 (No. Inventaris 04.2789) ditemukan di Desa Ketapang, Kecamatan Penengahan, Kabupaten Lampung Selatan (Gambar 4). Arca yang terbuat dari bahan perunggu berukuran tinggi $16 \mathrm{~cm}$ ini digambarkan dalam posisi duduk sedang bersemedi di atas lapik berbentuk kubus. Kedua kaki bertumpu pada bantalan padma. Posisi tangan ditekuk di depan dada dalam sikap memutar roda dunia (dharmacakramudra).

\section{- Arca Avalokiteswara}

Arca dengan nomor koleksi 695 (No. Inventaris 04.2775) ditemukan di Desa Ketapang, Kecamatan Penengahan, Kabupaten Lampung Selatan (Gambar 5). Arca setinggi $34,5 \mathrm{~cm}$ terbuat dari bahan perunggu. Arca dalam posisi berdiri di atas lapik padma.

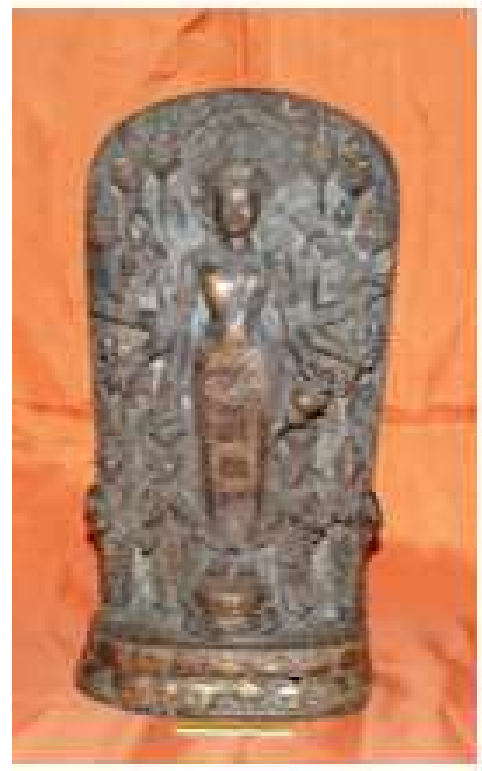

Gambar 5. Dyani Bodhisatwa Avalokiteswara ditemukan di Desa Ketapang, Kecamatan Penengahan, Lampung Selatan (Sumber: Dokumen Balai Arkeologi Jawa Barat, 2009).

Di belakang arca dilengkapi sandaran (stella) berbentuk persegi semakin melebar ke atas dan membulat pada bagian puncak. Di bagian atas stella terdapat hiasan bulan sabit di kiri dan bulan purnama di kanan.

\section{Bukti-Bukti Pewarisan Budaya}

Kebudayaan pada dasarnya merupakan kekayaan manusia yang bersifat abstrak (gagasan, pikiran, ucapan) maupun konkret (benda) yang berkaitan dengan kehidupan manusia itu sendiri. Kebudayaan tidak datang secara tiba-tiba. Kebudayaan terbentuk dan berkembang melalui proses belajar (Koentjaraningrat, 1990, hal. 180). Proses belajar dalam pembentukan kebudayaan pun bermacam-macam misalnya mulai dari internalisasi, sosialisasi, enkulturasi, hingga asimilasi (Koentjaraningrat, 1990, hal. 228-256). Begitupun dalam budaya teknologi logam pada masyarakat Lampung. Proses panjang dari masa prasejarah hingga masa kini telah menghasilkan suatu budaya teknologi metalurgi. Beberapa artefak budaya yang telah ditemukan di beberapa lokasi merupakan jejak-jejak yang tertinggal.

Jejak-jejak masyarakat penutur Austronesia di Indonesia telah banyak ditemukan. Menurut Peter Bellwood (2000, hal. 299-313), masyarakat penutur Austronesia berasal dari pesisir pantai China bagian selatan kemudian menyebar ke Taiwan dan ke wilayah lainnya di selatan dan barat. Penyebaran ke wilayah barat kemungkinan mengikuti alur darat hingga ke Thailand kemudian mengikuti aliran Sungai Perak yang berhulu di wilayah Thailand mengalir sampai di wilayah Kerajaan Perak Malaysia, dan akhirnya sampai di kawasan Sumatera bagian utara. Alur lain yang dimungkinkan adalah melalui jalur China bagian selatan terus ke Taiwan kemudian ke Filipina untuk kemudian ke Kalimantan dan terus ke Sumatera bagian utara (Wiradnyana, 
2017). Migrasi para penutur Austronesia tidak berhenti di Sumatera bagian utara tetapi terus menyebar ke selatan.
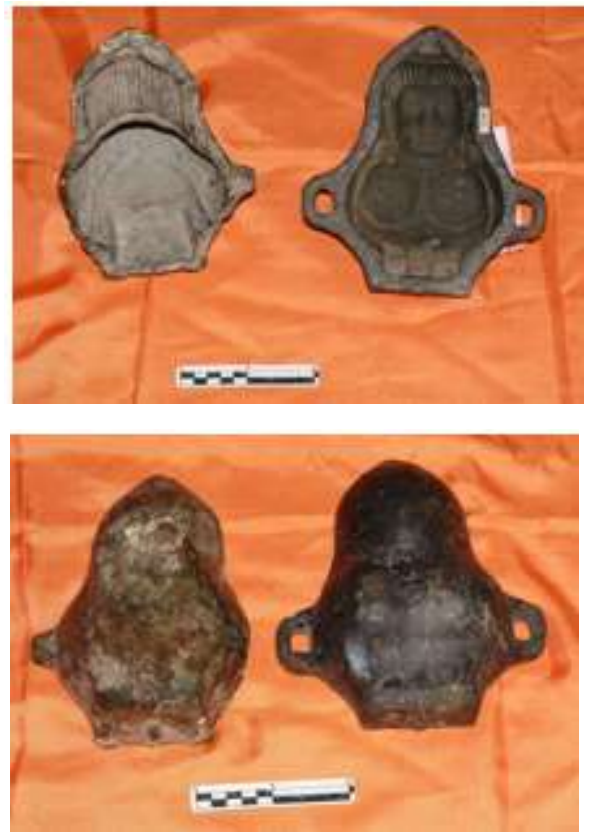

Gambar 6. Cetakan arca ditemukan di Desa Rajabasa, Kecamatan Kalianda, Lampung Selatan (Sumber: Dokumen Balai Arkeologi Jawa Barat, 2009).

Interaksi antara masyarakat penutur Austronesia dengan masyarakat nusantara memacu terjadinya perkembangan peradaban yang menyangkut berbagai bidang kehidupan. Organisasi sosial terbentuk dalam wujud kelompok-kelompok sosial di bawah kepemimpinan tradisional. Pada kelompok masyarakat tercipta spesialisasi kelompok misalnya kelompok yang mengurusi kepercayaan, undagi, petani, pedagang, dan pengarung samudera (pelayar). Kompleksitas masyarakat seiring dengan perkembangan kehidupan di lingkup regional. Kegiatan pelayaran dan perdagangan regional-global semakin marak di Kepuluan Nusantara. Tiga penanda mengenai kompleksitas budaya pada periode ini, yakni (1) penguburan tempayan, (2) benda-benda logam sebagai pengaruh budaya Dongson, dan (3) bangunanbangunan megalitik (Simanjuntak, 2015).
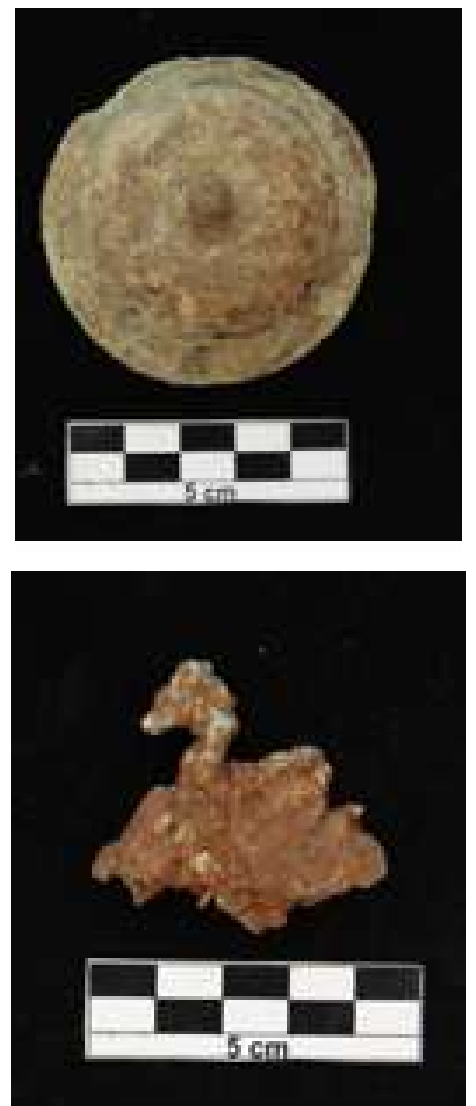

Gambar 7. Tutup perunggu dan terak perunggu yang ditemukan pada ekskavasi di situs Kuripan Saka (Sumber: Dokumen Balai Arkeologi Jawa Barat, 2018).

Salah satu jejak budaya masyarakat penutur Austronesia yang ditemukan di Lampung adalah benda-benda yang terbuat dari logam. Keberadaan benda logam di Lampung menandai adanya interaksi antara masyarakat Lampung dengan dunia luar. Benda-benda seperti nekara dan bejana perunggu pada awalnya merupakan barang dagangan. Selanjutnya benda-benda perunggu tipe lokal yang berfungsi untuk kebutuhan lokal banyak ditemukan. Bendabenda itu secara morfologis mencirikan era sejarah hingga masa-masa yang lebih muda lagi. Beberapa arca dewa-dewa Hindu dan 
arca Buddha banyak ditemukan di kawasan Lampung.

Benda logam yang pada awalnya merupakan barang impor, pada masa selanjutnya tampak sudah diproduksi setempat sehingga menunjukkan bahwa teknologi cetak tuang logam sudah dikuasai masyarakat Lampung. Salah satu benda tinggalan yang menunjukkan sudah dikuasainya teknologi logam adalah cetakan arca (Gambar 6). Alat ini ditemukan di Desa Rajabasa, Kecamatan Kalianda, Kabupaten Lampung Selatan (Tim Penelitian, 2009). Cetakan dibuat untuk mencetak arca kinara kinari. Kinara - kinari merupakan makhluk kahyangan yang berwujud setengah manusia setengah burung. Dalam kehidupan di kahyangan, mereka bertugas selain sebagai penjaga kalpataru juga sebagai seniman-seniman kahyangan yang memberikan pertunjukanpertunjukan kesenian di istnana kahyangan (Istanto \& Syafii, 2017, hal. 24). Pada beberapa relief lepas (tanpa ada kaitan cerita), digambarkan sedang memainkan beberapa instrumen musik. Cetakan terdiri dua bagian, bagian depan berukuran tinggi $18 \mathrm{~cm}$ lebar $11,5 \mathrm{~cm}$ dan dalam $6 \mathrm{~cm}$ dengan ketebalan $1 \mathrm{~cm}$. Bagian belakang berukuran tinggi $20 \mathrm{~cm}$ lebar $15 \mathrm{~cm}$ kedalaman $16 \mathrm{~cm}$.

Jejak teknologi logam ada juga yang ditemukan secara insitu berupa sisa-sisa pengecoran logam. Jejak tersebut ditemukan dalam ekskavasi di situs Kuripan Saka (Saptono et al., 2018). Situs Kampung Kuripan Saka secara administratif termasuk di wilayah Dusun Banyuurip Kuripan, Desa Kuripan, Kecamatan Penengahan, Lampung Selatan. Secara geografis berada pada posisi 5०43'37.36" LS dan 105'40'43.29” BT pada ketinggian $55 \mathrm{~m}$ di atas permukaan laut. Situs Kuripan Saka merupakan salah satu bekas permukiman masa Radin Intan dihuni pada tahun 1817 - 1828. Masa ini dalam periodesasi sejarah budaya di Indonesia termasuk dalam masa Islam-Kolonial.

Lahan situs dikelilingi sungai alam dan parit. Way Tulung mengalir di sebelah utara lahan situs. Pada sisi lainnya terdapat aliran parit. Jejak perkampungan yang masih tersisa berupa benteng tanah yang berada di sisi selatan dan utara. Posisi benteng sisi selatan memanjang dengan orientasi barat timur. Kedua ujung benteng berada di tepi parit. Benteng sisi utara juga berujung pada parit. Benteng sisi utara bagian luar terdapat cekungan (parit). Pengamatan di permukaan tanah menemukan beberapa artefak berupa pecahan keramik. Di sebelah utara ujung timur benteng sisi utara terdapat batu tegak berbentuk silindrik. Ekskavasi pada kotak LU 5 spit 3 menemukan benda logam berupa tutup dan di kotak LU 6 spit 3 ditemukan terak jejak pengolahan logam perunggu (Gambar 7).

Berdasarkan temuan benda-benda logam khususnya perunggu di kawasan Lampung terdapat perkembangan dalam hal cara mendapatkannya. Benda-benda logam prasejarah seperti nekara dan bejana perunggu didapatkan melalui sistem perdagangan. Artinya, benda-benda tersebut ada di Lampung karena hasil dari aktivitas perdagangan. Pada masa sejarah (masa Hindu-Buddha hingga Islam kolonial) sudah dapat memproduksi bendabenda perunggu. Teknologi percampuran, peleburan, dan pencetakan benda logam pada masa prasejarah belum dikuasai masyarakat Lampung. Migrasi masyarakat penutur Austronesia membawa pengetahuan tersebut dan selanjutnya diwariskan kepada generasi berikutnya.

Kebudayaan Dong Son dan beberapa kebudayaan lainnya di Asia Tenggara pada sekitar tahun 1000 SM sudah mengenal 
pengetahuan pengolahan perunggu. Teknik yang dikembangkan disebut dengan lostwax atau cire perdue. Teknik pengolahan ini merupakan proses yang sering diterapkan pada pembuatan arca dari material logam (misalnya perak, emas, perunggu). Metode cire perdue dilakukan dengan melewati beberapa tahapan dimulai dari pembentukan benda yang dikehendaki dengan bahan lilin, lengkap dengan bagian detailnya. Lilin tersebut kemudian dibungkus dengan tanah liat (clay) dan selanjutnya dipanaskan sehingga lilin menjadi cair. Selanjutnya, logam cair dituangkan ke dalam tanah liat yang telah terbentuk. Setelah dingin, tanah liat dipecahkan sehingga didapatkan benda yang dikehendaki (Wijaya, 2013). Pada masa prasejarah, dalam pembuatan benda logam juga diterapkan teknik corong (socketing technique). Teknik demikian menjadi ciri khas Asia Tenggara dan menunjukkan adanya perbedaan dengan yang diterapkan di Cina dan India. Selain metode cire perdue dan socketing technique, juga dikenal cetak langsung dengan menggunakan cetakan setangkup (Haryono, 1999).

Berdasarkan beberapa tinggalan yang ditemukan di kawasan Lampung terlihat bahwa ketiga teknik pengolahan logam tersebut telah diterapkan. Arca-arca perunggu yang pada bagian dalam terdapat corong menunjukkan teknik pencetakan sebagaimana pada kapak corong. Bendabenda keperluan sehari-hari seperti tutup, serta cetakan arca dan terak logam perunggu menunjukkan bahwa teknologi peleburan dan pencetakan logam pada masa sejarah sudah dikuasai masyarakat Lampung. Dengan adanya jejak-jejak benda dan jejak teknik pembuatan benda logam menunjukkan bahwa terjadi pewarisan pengetahuan dari masyarakat penutur Austronesia kepada generasi-generasi sesudahnya.

\section{SIMPULAN}

Benda-benda perunggu telah banyak ditemukan di daerah Lampung. Benda berupa nekara dan bejana merupakan hasil budaya Dongson yang kemungkinan bukan merupakan produk lokal. Pada masa-masa yang lebih muda telah ditemukan beberapa benda logam beripa arca. Pada masa yang lebih muda ini ditemukan pula jejak-jejak teknologi pengolahan logam. Cetakan setangkup yang ditemukan di Rajabasa dan terak perunggu yang ditemukan pada ekskavasi di situs Kuripan Saka menunjukkan bahwa pada masa itu masyarakat sudah mengenal teknologi cetak tuang logam. Berdasarkan tinggalan-tinggalan logam dan jejak teknologi logam terlihat bahwa ada jejak pewarisan teknologi dari masa prasejarah hingga masa-masa yang lebih muda lagi yaitu masa Hindu-Buddha hingga Islam-Kolonial.

\section{DAFTAR PUSTAKA}

Bellwood, P. (2000). Prasejarah Kepulauan Indo-Malaysia. Jakarta: Gramedia.

Fachruliansyah, I. (2018). Antropologi Biologi di Indonesia: Sebuah Penelusuran dan Kemungkinan Pengembangan. Antropologi Indonesia, 39(2), 90114.

Haryono, T. (1999). Dinamika Kebudayaan Logam di Asia Tengga. Humaniora, (10), 25-31.

Istanto, R., \& Syafii. (2017). Ragam Hias Pohon Hayat Prambanan. Jurnal Imajinasi, XI(1), 19-28.

Jusoh, A. (2016). Kebudayaan Dongson di Asia Tenggara: Satu Tafsiran Berdasarkan Penemuan Arkeologi. Purba - Jurnal Persatuan Muzium Malaysia, 35, $1-28$. 
Koentjaraningrat. (1990). Pengantar Ilmu Antropologi. Jakarta: PT Rineka Cipta.

Poesponegoro, M. D., \& Notosusanto, N. (2009). Sejarah Nasional Indonesia I: Zaman Prsejarah di Indonesia (R. P. Soejono \& R. Z. Leirissa, ed.). Jakarta: Balai Pustaka.

Saptono, N., Widyastuti, E., Rusyanti, Nuralia, L., Falah, W., \& Siswanto. (2018). Laporan Penelitian Arkeologi: Permukiman Masyarakat Keratuan Darah Putih di Sekitar Gunung Rajabasa Lampung Selatan. Bandung.

Simanjuntak, T. (2015). Progres Penelitian Austronesia di Nusantara. Amerta, Jurnal Penelitian dan Pengembangan Arkeologi, 33 (1), 25-44.

Tim Penelitian. (2009). Budaya Masa Pengaruh Hindu-Buddha di Kawasan Lampung. Laporan Penelitian Arkeologi. Bandung.

Wijaya, H. (2013). Nekara: Peninggalan Seni Budaya dari Zaman Perunggu. Humaniora, 4(1), 212. https://doi. org/10.21512/humaniora.v4i1.3431

Wiradnyana, K. (2017). Budaya Austronesia di Indonesia Bagian Barat Dalam Kaitannya Dengan Migrasi Out of Taiwan. Berkala Arkeologi Sangkhakala, 18(1), 22-39. https:// doi.org/10.24832/sba.v18i1.6

\section{HASIL DISKUSI}

\section{Pertanyaan}

\section{Ary Sulistyo (TACB Kota Depok)}

1. Lampung adalah wilayah di Sumatera yang paling dekat dengan Jawa. Melihat dari peninggalan yang ditemukan di Lampung, apa kaitannya dengan hunian Austronesia berbatasan dengan
Austroasiatik. Di utara Lampung ada Sumatera Selatan yang kalau tidak salah merupakan batas antara Austroasiatik dengan Austronesia?

\section{Eko Punto Hendro (Universitas Diponegoro Semarang)}

Mengenai budaya Dongson, apakah kebudayaan perunggu merupakan budaya martabat (status sosial, upacara)? Kebanyakan alat-alat perunggu berfungsi sebagai peningkat martabat, bukan untuk kepentingan praktis. Kepentingan praktis mungkin masih menggunakan batu.

\section{Jawaban}

1. Banyak situs-situs yang kelihatan seperti batas di daerah Sumatera terutama situs megalitik. Di dalam buku Megalitic Remains in South Sumatra yang disusun oleh van Der Hoop, kawasan Sunda dimasukkan sebagai kawasan "South Sumatra". Sehingga menurut Hoop Sunda merupakan batasnya. Banyak situs di Jawa Barat yang berparit, memiliki pola hunian yang mirip. Mengenai bentuk rumah, rumah Austronesia berbentuk rumah panggung. Di Sunda memiliki rumah tradisional panggung, sementara di Jawa rumahnya tidak panggung. Mungkin pada masa yang dahulu, batas tersebut berada di daerah Sunda, kemudian bergeser ke Lampung. Di Jawa Barat tidak ditemukan dolmen, sementara banyak ditemukan dolmen di Lampung dan juga di wilayah timur Indonesia. Hal tersebut mungkin bisa dikatakan sebagai anomali yang perlu diteliti lebih lanjut. Belum ditemukan manusia sezaman Austronesia di Lampung. Untuk batas tersebut memang harus dikaitkan dengan manusianya. 
Belum adanya ekskavasi lebih lanjut di Lampung. Tinggalan tertua yaitu dari masa neolitik hanya ditemukan di permukaan sehingga belum ditemukan tinggalan prasejarah yang secara stratigrafi menunjukkan kronologi. Temuan paling tua di Lampung berasal dari abad ke-7 M.

2. Di Lampung, temuan logam besi banyak ditemukan, namun untuk logam perunggu hanya ditemukan dalam jumlah yang sedikit. Sehingga mungkin yang diproduksi memang benda-benda yang bermartabat. Pada satu situs di Lampung, ditemukan sebuah terak perunggu bersamaan dengan temuan yang mirip dengan tutup pedupaan. Di Lampung daerah selatan, juga ditemukan cetakan arca yang dapat memproduksi benda ritual. Di Lampung juga hanya menemukan tiga alat perunggu yaitu dua nekara dan satu bejana. Bejana perunggu merupakan benda yang hanya sedikit ditemukan. Pertama kali ditemukan di wilayah Kerinci, kemudian Lampung, Madura, dan Subang. 